\title{
Semantic and Cognitive Communicative Aspects of Abbreviation in the Modern English Discourse Varieties
}

\author{
Alla Petrovna Minyar-Beloroucheva ${ }^{1}$, Polina Igorevna Sergienko ${ }^{1}$, Elizaveta Alexandrovna Vishnyakova ${ }^{2}$ \& \\ Olga Dmitrievna Vishnyakova ${ }^{1}$ \\ ${ }^{1}$ Lomonosov Moscow State University, Moscow, Russia \\ ${ }^{2}$ Tula State Lev Tolstoy Pedagogical University, Tula, Russia \\ Correspondence: Polina Igorevna Sergienko, PhD (Philology), lecturer of the Department of English for the \\ Humanities, Faculty of Foreign Languages and Areas Studies, Lomonosov Moscow State University, Moscow, \\ Russia. E-mail: poserg@bk.ru
}

Received: October 11, 2019 Accepted: November 8, 2019 Online Published: December 10, 2019

doi:10.5539/ijel.v10n1p26 URL: https://doi.org/10.5539/ijel.v10n1p26

\begin{abstract}
The paper focuses on the integrated approach to investigation of abbreviations that are referred to the units of secondary nomination. Abbreviations facilitate the communication process due to the principle of economy in language. Abbreviation that goes back to ancient times is one of the most actively performed and intensive processes in the English language. The use of abbreviations is connected with both linguistic and extra-linguistic factors that to a great extent determine a variety of discourse under consideration and ways of decoding certain linguistic units of abbreviated form, where context plays the most important role. There exists a number of structural types or models, according to which abbreviations are created in order to function as separate linguistic units used in the communicative process, where in the course of time they tend to acquire new independent and sometimes unique semantic properties. In socially determined professional registers certain regularities of abbreviations constructing and functioning are observed. In this paper most of the examples refer to such discursive varieties as politics, public relations, business and to a less extent medicine. Interdiscursivity that in this particular context means actualisation of the same abbreviated form within different discursive varieties seems to be one of the basic features of the abbreviation process under analysis.

From the cognitive point of view, the study of abbreviated forms is based on the theory of propositional structures in the human mind manifestation. The cognitive approach correlates with linguistic semiotic and general semiotic issues, as at the iconic level of representation an abbreviation can be considered a starting point for creation of new entities and images, based on the results of perception, and the object for subsequent interpretation. This involves operation with fragments of reality, subject to reflection in the domain of human consciousness. Cognitive communicative approach takes into account different formats of knowledge that present the foundation for abbreviations active use and distribution.

The Internet as a new medium for the language existence, as well as application and formation of human thought, plays an important role in optimizing messages as well as the communication process as a whole due to abbreviation techniques.
\end{abstract}

Keywords: abbreviation, discourse, cognition, proposition, communication, integrated approach, interdiscursivity

\section{Introduction}

Abbreviation can be clearly stated as a powerful means in the development of languages. The process of abbreviation can be traced as far back as Ancient Egypt, when contracted linguistic forms consisting of more than one element emerged. As for the system of English abbreviations, it has evolved over several centuries. With the letter ' $\mathrm{p}$ ', standing for 'pæt', functioning on the first page of the Anglo-Saxon manuscript Beowulf, commences the long history of abbreviations in the English language. Later on, in medieval manuscripts abbreviations became more numerous. The number of abbreviations began to increase considerably in the nineteenth century with the development of telegraph (González \& Cannon, 1994), as this means of communication demanded contractions to lower the price of the message transfer. At that time, they were recognized as independent lexical units. However, 
they were few in comparison with the avalanche of abbreviations at the turn of the Century. David Crystal writes: "Abbreviations, one of the most noticeable features of present-day English linguistic life, would form a major part of any super dictionary. Often thought to be an exclusively modern habit, the fashion for abbreviations can be traced back over 150 years" (Crystal, 2003, p. 120). A considerable amount of abbreviations appeared in the twentieth and the twenty first centuries in various types of discourse, for example, in business, public relations, politics, etc.

Abbreviations break existing stereotypes of the lexical syntactic structures and create the new ones by the replacement of the long lexical units by their short forms that may sometimes carry even more information than the conventional lexical units (their prototypes), though being regarded as units of secondary nomination. From the terminological point of view, it should be noted that in this paper the term "abbreviations" is referred to various types of contracted forms, ever existed and realized at the level of natural human language, comprising both letters and syllables, as well as elements of other semiotic systems (e.g., figures or emoticones). The issues concerning various types of abbreviation (Crystal, 2003, p. 120) are taken into consideration as well.

Widespread creation and use of abbreviations as a materialized and verbally represented lingual-mental process due to the emergence of saving mental power and attitude can find the explication both by the appearance of new phenomena and their contracted nomination requirements in terms of the tendency to reduce existing nominative units for practical purposes (Vishnyakova et al., 2019). This is also explained by the need for creativity and search for optimal solutions, inherent in human consciousness and typical of human nature. From the point of view of cognitive-discursive approach, the formation of these nominative units in language can be considered to be the phenomenon related to realization of verbalized mental processes. They are referred to particular varieties of discourse structuring, due to the needs of the society and certain discursive limitations (Van Dijk, 1997; Van Dijk \& Kintch, 1983; Couthard \& Montgomery, 2015).

It should be mentioned in this connection that transformations in the abbreviations area are referred to the heuristic character of the phenomenon in question, determined by message optimization and efficient information transfer requirements within the linguistic cultural community. The heuristic nature of the process under investigation can be considered to be the basis for its linguistic functional peculiarities manifestation in discourse, while paying special attention to the abilities of the representatives of the language community to provide adequate interpretation in the course of abbreviations decoding. For example, the motivating factors for the acronyms realization in business discourse are the need to save time and language efforts, as well as the desire for an "on-screen" arrangement of the text and its components subject to compression. This leads to the emergence of new abbreviations of more general and more specific nature, that is characterizing the sphere of business as a whole and as the totality of individual professional areas. The need to study and properly organize abbreviation materials can be illustrated and confirmed by the following reasoning, accompanied by the description of the state of affairs in business: "First of all everyone knows that in today's business world we are all confronted daily with a variety of common (and not so common) abbreviated terms. Whether these terms are communicated in written and verbal form, confusion can arise, since most of them frequently convey several different meanings. For example, IBM is a three-letter word that is quickly identified throughout the world as initials for International Business Machines. However, these same three letters also stand for the Institute for Burn Medicine, Industrias Biologicas Mexicana (Mexican Biological Industries), intercontinental ballistic missile, and the International Brotherhood of magicians. And the two-letter words, IB and IM, have a list of several dozen possible spelled-out forms" (Rosenberg, 1992, p. VII).

It should always be borne in mind in this connection that abbreviations constitute a two-fold process, being both natural and artificial in its manifestation as it constitutes certain difficulties in terms of pronunciation or semantics identification (Nilsen, 1981). Nonetheless abbreviations proceed naturally in different varieties of discourse and serve successfully to substitute their prototypes both at the system of language and actual speech levels.

\section{Material Studied}

In the course of the investigation the material taken from the Mass Media sources was subject to the analysis. First and foremost, representations of the political discourse, as well as samples of public relations and business varieties of discourse, belonging to different genres and social environment reference were taken into account. The materials under consideration are characterized by both general and specific qualities that determine the nature and mode of abbreviation properties manifestation at the systemic and discourse levels.

It should be mentioned in this connection that in spite of the fact that primarily written texts from printed and the Internet sources were taken into consideration, most of them have been designed and created as interactive issues, 
possessing linguistic peculiarities and general discursive characteristics that help establish contact with the target audience (the reader) and in case of the Internet presentations may get an immediate feedback from the receiver. And - which seems to be most important within these terms - the Internet users may have access to various data that help to decipher messages and meanings transferred by abbreviated forms via using hypertext powers and abilities.

One more important point should be taken into account within these lines, which concerns the analysis of lexicographic data, i.e., dictionaries and linguistically oriented reference-books that contain the materials dealt with the notion of abbreviation and its types definitions as well as samples used for exemplification. One has to take into account invaluable sources like the Merriam-Webster dictionary, Longman Dictionary of English Language and Culture, Longman Dictionary of Contemporary English, McGraw-Hill Dictionary of Business Acronyms, Initials, and Abbreviations and others that contain the information necessary for abbreviation studies. At the same time in the course of the investigation much attention has been given to the Internet dictionaries and other materials, where one can find samples of actual speech realizations of the contracted forms in question and the way they are realized in contexts that belong to certain discursive varieties.

It should be emphasized that in some cases we find it necessary to refer to the Internet sites that demonstrate the process of abbreviation development and their discourse representations peculiarities due to the users' approach and evaluation. Thus, the issue concerning the MLE contracted form usage reveals a variety of its decoding possibilities and not only get into the linguistic context of its realization but also keep abreast of its sociocultural context and situational communicative peculiarities. As we proceed from the premise that abbreviation as an integrated dynamic phenomenon, in terms of language and mental structures interaction, to a great extent reflects some basic trends in the society development and their potential to be represented at the verbal level. Thus, various discursive characteristics based on the real-life representations of the interactive character should be taken into account in the course of abbreviation analysis.

As for the theoretical foundations of the investigation, in the process of abbreviations analysis we turned to the works by famous linguists and representatives of the Humanities area, paying attention to this domain of human knowledge and approaching the research procedure from different perspectives. In other words, the material that contains both practical and theoretical issues concerning abbreviation is on the one hand enormous, while on the other hand, it should be noted that not all the aspects of abbreviation have received all the attention they deserve so far, especially those referred to the discursive and cognitive properties of the abbreviation process.

\section{Area Description}

As has been mentioned above, at present abbreviation is regarded as one of the ways of language development. In the more traditional way at the linguistic structural level the crux of the matter consists in breaking the old word structure and creating shorter and easily perceptible language forms to be later lexicalized and in the course of time become part of the national language vocabulary.

Thus, in the dictionaries abbreviation is accompanied by the following definitions: "Middle English abbreviacioun "contraction, shortening", borrowed from Anglo-French abreviation, borrowed from Late Latin abbreviātiōn-, abbreviātiō, from abbreviāre "to abbreviate" + Latin -tiōn-, -tiō, suffix of action nouns. Thus, derived from the Latin word 'brevis' and translated as 'short', the term means a concise form of lexical units that permits to perceive part as a whole; “ 1 . A shortened form of a word, such as 'Dr' for Doctor or 'PTO' for 'please turn over' (URL: https://www.merriam-webster.com/dictionary/abbreviation). The dictionary also indicates that some of the abbreviations can only be used in writing, and not in oral speech - so they are marked accordingly.

The Merriam-Webster dictionary provides such examples as 'Amt' as an abbreviation for 'amount' and 'USA' for the United States of America to illustrate that abbreviation is a shortened form of a written word of phrase used in place of the whole word or phrase. The second suggested meaning is the result of abbreviating something, the abridgement as in "I know you would not be satisfied with an abbreviation of its contents, and you shall have the whole, save, perhaps, a few passages here and there of merely temporary interest to the writer" by Anne Brontë (URL: https://www.merriam-webster.com/dictionary/abbreviation). In modern English abbreviations can also be classified into contractions and initialisms. Initialisms in their turn are subdivided into acronyms and alphabetisms. Under contractions we usually understand abbreviations that are coined by the way of omitting several letters or syllables and merging the initial and final letters as well as abruption of several parts of a word. And it goes without saying that the most recent example within these terms is "Brexit".

Abbreviations are not homogeneous linguistic units. For instance, it is a well-established fact that within abbreviations initialisms are subdivided into alphabetisms and acronyms. Acronyms are constructed from the first letters of long phrases: PR for public relations, CEO for Chief executive officer, OSCE for Organization 
on Security and Cooperation in Europe, etc. Some acronyms are pronounced as words: WHO for World Health Organization, WEU for Western European Union, SHAPE for Supreme Headquarters Allied Power Europe, etc.

The prior task for the current investigation is to identify the relevance of abbreviations in different varieties of the English discourse, with special attention to business, political and public relations discursive spheres. Within the abbreviations linguistic field, it is possible to classify initial abbreviations as well as letter omissions, including that of vowel and consonant types. Some abbreviations are created by leaving out all but the initial letters of the word. Such abbreviations usually end in a period (as in "univ." for "university", and "gov." for "government"). Other abbreviations are made by dropping middle letters of the word as "atty." for "attorney". Otherwise stated, among the general functions of abbreviations is their undeliberate use for the purposes of saving space in written texts presentations and time preserving when spoken orally, to elude duplication of complicated words and phrases, or to conform to conventional usage in certain types of discourse. In applied and cognitive linguistics abbreviation process is studied in terms of corresponding texts and types of discourse to reveal the lexical structure and cognitive nature of the contracted forms (Minyar-Beloroucheva et al., 2018).

While discussing the problems of abbreviations emergence and functioning in a linguistic cultural environment we consider them to be the constituent part of language realized according to its regular norms, that find their actualization as well at the discursive level, first and foremost due to their unique functions. For instance, taking into consideration the symbolic properties of abbreviations it should be mentioned that in some cases a symbol is interpreted as a synonym for an abbreviation which leads the abbreviations analysis out of linguistic boundaries and brings it to an interdisciplinary level of study. It is a well-established fact that there is a great difference between symbolic and linguistic semiotic issues, as symbolic meaning of linguistic expressions is a highly conventional and occasional substance. At the same time some abbreviations, especially in the political discourse, clearly distinguished for its manipulative character (Van Dijk, 2008), may acquire symbolic functions and be used as the "marked constituents" of the discursive space in question, referring to cultural and professional communicative spheres.

Being faced with the situation one should always bear in mind that in most cases special preparation and deep understanding of the content of the statement are necessary in order to decipher the abbreviation and interpret it adequately (Vishnyakova, 2018). And quite on the contrary, in a number of professionally controlled and restricted situations where certain vocational terms are used both by qualified specialists and by ordinary consumers, not provided with special tools to decipher the abbreviated message accurately and unambiguously. Abbreviations decoding can be considered to be quite natural and acceptable, or in some cases totally unacceptable. Thus, for instance, in some cases of medical information transfer there exist special rules and limitations in the abbreviation use so that not to mislead those users who cannot decrypt the abbreviation correctly, which can even lead to disastrous consequences. Thus, "Abbreviations are not used on informed consent and patient rights documents, discharge instructions, discharge summaries, and other documents patients and families receive from the hospital about the patient's care. No abbreviations of any kind should appear in informed consent documents, patient rights documents, and discharge instructions. These documents are meant for the patient and every effort should be made to increase the readability and clarity of the documents" (URL: https://www.jointcommissioninternational.org/use-of-codes-symbols-and-abbreviations).

In other words, the area of abbreviation studies seems to be broad and complicated in terms of its cognitive, communicative, semantic and functional aspects interrelation and the methods applied for the analysis in modern linguistics, that seeks their manifestation in the integrated approach domain.

\section{Methods and Techniques}

The investigation of abbreviation process presupposes the use of the following methods and techniques for the sake of functional, semantic and cognitive communicative approaches application:

- the method of lexicographical analysis, which is based on the study of the specialized dictionaries of abbreviations and acronyms, and which enables the learner to analyze abbreviations per se and their derivatives;

- the method of structural and semantic analysis aimed at the study of the linguistic meaning of contracted forms elements and the meaning of the whole word appeared as the result of abbreviation process to establish structural and semantic correlation of the indicated objects of study;

- the methods based on the cognitive conceptual and cognitive discursive approaches, taking into 
consideration both sociocultural phenomena, as well as linguistic and mental structures representation process. It should be mentioned within these terms that the category of linguistic creativity, which concerns with the creative potential of language and corresponding culture, based on the use of language as the means of human knowledge representation, closely connected with interpretation and understanding processes;

- $\quad$ the method of contextual analysis which includes various types of context investigation, i.e. linguistic context, which takes into consideration semantic and cognitive pragmatic peculiarities of the utterance that contains an abbreviated form, situational context, social cultural context and cognitive context. It refers to the domain of knowledge that includes the entire cognitive experience of a person as an individual and as a representative of certain linguistic cultural community.

Thus, as can be seen from the list above, a number of appropriate methods and techniques should be used in the course of the research being done for the purpose of abbreviation analysis on the basis of the integrated approach to the linguistic phenomenon in question. It should be added that in the course of the investigation one should proceed from the premise that both the process of codifying as well as the process of decoding abbreviated structures deserve special attention in terms of integrated approach application.

\section{Results and Discussion}

As has already been stated, abbreviation as the process of contracted linguistic forms creation in terms of speech process optimization and modelling is characterized by its conformity and limitations in terms of linguistic regularities typical of the language it belongs to. Thus, abbreviation plays an important role in the process of information transfer within the scope of various types of human discursive activity. It should be emphasized that in the course of time abbreviations of various types while functioning in speech as contracted units may acquire specific properties as independently functioning nominative structures.

In this paper we are trying to make an attempt to describe the abbreviation phenomenon within a number of discursive spheres. For example, while taking into consideration such humanitarian issues as the political discourse or the public relations discourse, one comes across abbreviations, which in their meaning possess the peculiarities of terms functioning in the corresponding area as special notions, typical of a certain discourse representation. The process of creation and decoding the linguistic units in question may sometimes cause difficulties in the written and oral forms of speech in some cases facilitating, and sometimes complicating the process of transmitting information and communication. As is well-known, abbreviations creation is conjugated with other mental-lingual procedures designed to reflect, fix, decipher and explain the meanings of the notions indicated by contracted forms of various structural and semantic types.

For example, the analysis of the political and PR varieties provides for the possibility to identify the types of abbreviations that function within their speech representations that can be distributed according to their composition type.

The prime source for abbreviations is the multi-element phrases among which three-element units are most widely spread: ECJ, ABM, MFN, etc. Next come two-element abbreviations: (EU, RS, US, PR) and five-element structures (NAALC, NAAEC), followed by the group of four-element units (FIFA, NACC), and very rarely six-element structures, like EPISTER, STANAG. UNESCO. An example of one-element abbreviations, as in "C", "A" should be also adduced within these lines.

Special attention should be given to homonymic abbreviations, such as $\mathrm{C}$, under which different notions can be applied, such as compromise, constituent, controversy, conservative, etc. It is a matter of common observation that context is of vital importance in this connection, as well as other discursive characteristics dealt with not only linguistic but also extralinguistic peculiarities of the units in question functioning. One more example of abbreviation homonymy is a well-established fact that the MLE abbreviation has acquired a wide-spread application in the English language, to be associated with Multicultural London English phenomenon, i.e., the new ethnosociolect, appeared in Modern English (Kerswill, 2017). The same linguistic sign may be used in the other meanings: mobile logistics element, missile launch envelope, mobile launcher equipment (in military terminology), microprocessor language editor (in technology), maximum likelihood estimate, MultiLine Entry field (IBM, OS/2) (in computing), Mediated Learning Experience, managed learning environment (in education) (URL: https://translate.academic.ru/MLE/en/ru/).

Obviously, the system of formal criteria underlying the classification of abbreviations can only be considered as an element of the first stage of the study, the most important part of which, at the same time, is considered to be its sociocultural component. Due to the current state of society development it is represented in various 
discursive activities of people: "In modern times, breakneck progress in electronics, space exploration, and data processing brought new concepts, new projects, and new instruments. It also brought new acronymic forms to save precious inches of newsprint and precious seconds of broadcast time, to serve as cloaks of military secrecy and as spotlights on products, ideas, and programs that the public was expected to support, admire, or purchase" (URL: https://muse.jhu.edu/article/460376).

Thus, context seems to be the most vividly identifiable parameter for adequate interpretation of abbreviated forms in terms of meaning. At the same time as for the cognitive approach implementation it should be mentioned that this doesn't mean to say that context is the only possible way to decipher the content of the message transferred by abbreviation forms. There are conventional abbreviations, well-known to everyone due to their extensive use and long-term existence in language. They are lexicalized, socialized and perceived by professionals as well as common speakers as the linguistic units associated with a certain type of discourse they belong to, and in the majority of cases may not be regularly accompanied with immediate associations in terms of their prototypes semantic constituents. It may also entail indirect and sometimes ambiguous references to the original full forms. A great number of abbreviations have acquired the ability to function as lexical units proper, characterized by their own systems of lexical phraseological and morphological syntactic peculiarities and, as has already been stated, may present themselves as separate cognitive and linguistic structures. The examples are EU, IBM, IFM, etc.

As the analysis has shown, abbreviated forms may consist of both letters and figures. This phenomenon is the evidence of the evolution of the abbreviation system, where in some cases letters alone are not sufficient to render the meaning of the units in question or figures may stand for the whole complexes of letters to indicate syllables and structural parts of lexical units subject to abbreviation. Otherwise stated, we may witness the process of the polycode system development, to a great extent concerned with electronic communication, which lies in the sphere of different semiotic systems interaction. Thus, there exist two types of acronyms and abbreviations that comprise figures in their structure: G8, G20, i.e., full phrases are created via the elements of the two sign systems combining. Figures are part of the abbreviation constructions, though in other cases they are words of independent semantics.

One more abbreviation type comprises abbreviations which include figures functioning as part of words and phrases: $a 4 c, 4 u, 2 u$ etc. g8debate. It is a well-established fact, that David Crystal in his book 'Language and the Internet' distinguishes a certain variation of the Internet discourse, called Netspeak due to its characteristic features. The following examples that comprise letters only are adduced by the outstanding author: BBS ('bulletin board system'), BCC ('blind carbon copy'), DNS ('domain name system'), FAQ ('frequently asked question') (Crystal, 2001, p. 84). As for abbreviations comprising letters and figures, the following linguistic material is provided within these lines: W3C ('World Wide Web Consortium'), Go2Net etc. The frequency of occurrence and the shift from the Web into everyday speech is the basis for the new variety of English to be recognized, which facilitates communications and makes the communication process more optimized and effective.

Thus, taking into consideration the actual text material, that is representation of discourse under consideration, we may come across the following examples, illustrating the process of abbreviations functioning: "At the heart of this regime continues to stand the UN Universal Declaration of Human Rights. Although the 1945 UN Charter urged the promotion of "universal respect for, and observation of, human rights and fundamental freedoms for all', it failed to specify the human rights that states had to guarantee and respect" (Heywood, 2011, p. 221); "Bilateral treaties are concluded between two states, such as the START treaties through which the USA and Russia have agreed to reduce their stockpiles of nuclear weapons" (Ibid., p. 334).

In the text fragments above one can find abbreviations like UN, USA, START that do not need any specifications or particular comment, as all of them seem to be familiar to the reader and are based on the background knowledge possessing typical of the present-day linguistic cultural community that uses the forms under consideration quite naturally. As has already been stated, the human society needs abbreviations because the need for economical use of language tools is extremely acute in a number of registers and discursive varieties: "Succinctness and precision are highly valued, and abbreviations can contribute greatly to a concise style. They also help to convey a sense of social identity: to use an abbreviated form is 'to be in the know' - part of the social group to which the abbreviation belongs... It would be strange indeed to hear someone routinely expanding BBC, NATO, USA, AIDS, and all the other common abbreviations of contemporary English" (Crystal, 2003 , p. 120). At the same time as for some other abbreviated forms, to be clearly understood by the recipient one needs to supply their use with decoding and explanatory issues. Thus, for instance, in the above text fragments, taken from the social-political sphere, such cases as NPT (Nuclear Non-Proliferation Treaty) and ICJ 
(the International Court of Justice) may serve as good examples of the need for the correct interpretation.

It should be mentioned in this connection that while taking into consideration the structural peculiarities of abbreviated forms typical of a certain discursive variety of English, one can distinguish various types of abbreviated forms functioning, for example, in the political discourse. Thus, within this type of discourse, one may face hybrid abbreviations, such as R2P: "The idea of a 'responsibility to protect', or R2P, has been widely used by those who wish to provide a legal basis for humanitarian intervention" (Heywood, 2011, p. 344). And the figures in this type of abbreviated forms can be both Arabic and Roman. They influence the visual perception of the meaning and depend on various nomenclature limitations, which can be exemplified by units like START1, START2, START3 and WWI, WWII. This is illustrated by the following contexts: "Only two permanent members of the P-5 - the UK and France, its least powerful members - have ratified the Rome Statute. Not one of the nuclear powers outside Europe has ratified the treaty, meaning that the ICC is dominated by European, Latin-American and African states. The opposition of the USA to the ICC has been particularly damaging (Heywood, 2011, p. 50).

One more type of recent abbreviations deals with the units used in the plural form: "It did this by negotiating bilateral immunity agreements (BIAs), sometimes called 'Article 98' agreements, with as many countries as possible, under which neither party would transfer citizens of the other country to the jurisdiction of the ICC. Over 100 BIAs have been negotiated, even though their legal status is unclear" (Heywood, 2011, p. 350). As for the syllabic structure of abbreviations, they are widely used, for example, in the political discourse: STANAG, which consists of 'stan' and 'ag', a two-element phrase which means 'Standartisation Agreement'. Each of the elements of the phrase is written with the capital letter. One more example is AFRICOM, which stands for the three-element phrase-US African Commander. As is seen from the example, in this case the first element is omitted. The most difficult for immediate decoding and understanding are abbreviation forms that are based on other abbreviations, i.e., "abbreviations within abbreviations", which can be called "double abbreviations": NRF (NATO + Response Force); CCC (Customs Cooperational Council) - CCCN (Customs Cooperational Council Nomenclature); CAD (Computer-Aided Design) - CADCOM (Computer-Aided Design for Communication). Otherwise stated, there exist a number of abbreviation types that are used to facilitate the process of communication and are motivated by the principle of linguistic economy realization (Crystal, 2003, p. 120).

Otherwise stated, the process under consideration concerns with onomasiological structures creation that from the cognitive point of view refer to propositional structures or models. In other words, the linguistic units of various levels may be semantically associated with each other only in case they are included into the propositions codified and preserved in a certain specific way in the human mind, namely, in a set of numerous interconnected network nodes of human memory. The most important quality of propositionality is the disintegration of the integral (the holistic) as well as the ability to analyse the phenomena in terms of their relationships with each other and with the outside world, taking into consideration such parameters as identification, identity, nomination and characterization (Arutyunova, 1976; Kubryakova, 1986). One of the most significant issues concerning the present investigation is the assumption that proposition may be regarded as the mental structural basis of an abbreviation determined by the nature of its prototype reference to the onomasiological model chosen for the contracted form creation. It should be borne in mind that the cognitive approach enables the learner to identify the proposition notion due to the fact that principles of perception are also included into the scope of the analysis. It means that while creating and decoding abbreviation forms various types of knowledge are included into the processes of speech production and speech perception as well as understanding and interpretation.

It should be mentioned that cognitive approach correlates with linguistic semiotic approach, as the iconic representation of an abbreviated form serves as an incentive for generating associations as a result of its perception. Special attention should be paid to the necessity to use unambiguous and correct language display for the recipient to get the complete information contained in the abbreviated unit. Thus, as has already been said, an abbreviation is a reduced, folded structure, which at the cognitive level presents itself as the structure of storage and knowledge processing in the human mind. While analysing the abbreviation process in the English language we proceed from the premise that from the cognitive point of view each linguistic unit that represents the activities of human consciousness should be regarded not only as a carrier of a certain quantum of knowledge, but also as an incentive and mental basis for representing a whole integrative knowledge complex (Bates, 1979). This complex contributes to the implementation of cognitive operations of a higher level. As it has been stated above, in the process of mental representations formation as well as their linguistic representation depend on the perception and understanding of the world around us and the recipient's relevant knowledge. In case of abbreviated forms this concerns both the level of language system and the actual speech functioning. Thus, while 
dealing with the notion of discourse one should bear in mind that the linguistic peculiarities of the units in question manifestation to a great extent depends on the extralinguistic reality, which is a significant factor determining the specifics of updating linguistic meanings and forms.

As has been stated above, specialists in their professional interaction resort to most concise and effective mode of communication and means of rendering ideas. For example, taking into consideration the public relation sphere of abbreviation functioning, it should be mentioned that among the first abbreviations created in the domain of PR is the name of the area itself. Generally understood as public relations, this word combination has produced a number of definitions, that reflect its different aspects and characteristics (Sergienko, 2018). For example: "Public relations is the management function which evaluates public attitudes, identifies the policies and procedures of an individual or organization with the public interest, and plans and executes a program of action and communication to earn understanding and acceptance" (URL: https://www.marketingteacher.com).

Public relations is a strategic communication process that builds mutually beneficial relationships between organizations and their publics (URL: http://www.prdefinition.prsa.org). It should be added in this connection that abbreviation itself finds its extensive representation in public relations area though, according to lexicographic sources, even within this particular domain occupies only the third place after PR — press release and PR — Pier and is used to express a number of other meanings (URL: https://www.abbreviations.com/pr). At the same time this doesn't mean to say that PR as referred to public relations is registered in all the dictionaries at all. For example, in the "McGraw-Hill Dictionary of Business Acronyms, Initials \& Abbreviations" this contracted form refers to 15 different meanings (for instance, Panama Railroad, Philippine Airlines, Physical Record, Price Rate, etc.) and does not include public relations in spite of the fact that the area in question is to some extent connected with the area of business and business organisations (Rosenberg, 1992, p. 253). Otherwise stated, there exist certain limitations of extralinguistic character as far as abbreviations decoding and functioning are concerned. At the propositional level the situation with multiple choice dependent on the contextual peculiarities and associative features comes into existence.

Here are examples taken from the PR contracted terminological units, representing marketing realia and activities. The ATL/BTL abbreviations are commonly used in budgeting, where under ATL, or 'Above the line' a type of advertising is understood that is 'talking at you', e.g., television, radio, posters. These are the traditional forms of advertising that organizations pay for. The money allocated for this type of promotion is generally included into marketing. BTL means 'below the line', or advertising that is 'talking to you', e.g., direct mail, point of purchase, leaflets. Here PR practitioners presuppose the use of free means of convincing the audience of the key ideas in the message conveyed.

The sphere of PR also provides some examples of abbreviations, which include contractions with the combination of letters and figures, like 3Rs in marketing: Reach, Repetition and Relevance to ensure a successful marking or a PR campaign; or the 3 Is: Information, Integrity and recently added Interactivity to describe the approach of PR strategy and availability of their message in the new age of technology. The third I as interactivity has come with the demand of the market for the consumers to communicate with the organization on par. Some other acronyms include examples, such as B2B, B2C, G2C, G2G, G2B, B2G and C2C, where '2' stands for 'to' to mean the direction from the sender of the services/products to the receiver: B2B (Business to Business), B2C (Business to Consumer), G2G and G2C, etc.

The emergence of new words and abbreviations in particular are also explained by new notions and concepts coming into the language (Minyar-Beloroucheva, 2015). Here we can trace the following examples. The idea of POS and POS-materials became important with the development of marketing technologies: "POS (Point of Sale) - Point at which a sale is made, the ownership (and usually the possession) is transferred from the seller to the buyer, and indirect taxes (such as VAT) become payable. Commonly, a retail outlet" (URL: http://www.businessdictionary.com).

The newly emerged sphere of social media prompted the appearance of SMA, or Social Media Audit and SMM, social media marketing. The Internet Marketing teacher explains the need for the new experts: "So what a digital marketer needs is a tool to audit social media within the competitive environment, i.e., relative to competitors. The digital marketer will be trying to work out the best way to 'feed' the digital marketing funnel, and he or she will also need to monitor/measure any discussions about his or company. This is where a social media audit fits in" (URL: https://www.marketingteacher.com). SMM, or Social media marketing, refers to the process of gaining traffic or attention through social media sites. Social media itself is a catch-all term for sites that may provide radically different social actions. For instance, Twitter is a social site designed to let people share short messages or "updates" with others. Facebook, in contrast is a full-blown social networking site that allows for sharing updates, 
photos, joining events and a variety of other activities (URL: https://thirddoormedia.com/news).

Generally speaking, for the discursive variety of public relations the extensive use of contracted word forms allows to speed up communication, economize linguistic effort and screen space. The use of contracted lexical forms, such as marcomm, ATL, BTL, PLC, FMCG. PEST factors, SMM, and others viewed in this paper, testify to the general trend to save on the characters used in oral and written speech within professional communication. In other words, the discursive approach based on the linguistic and extralinguistic factors interaction, allows not only to detect and describe the main characteristics of abbreviation process in this type of discourse, but also to identify the potential of abbreviated forms usage in order to optimize the process of information transfer and correct decoding in order to further understand and interpret abbreviations adequately. It should be mentioned within these lines that the problem of interdiscursivity (Courtine, 1981) inevitably arises in this connection as there exist a great number of abbreviated forms used within the scope of different discursive varieties to express certain meanings.

\section{Conclusion}

Thus, in the course of the analysis it has been clearly shown that abbreviated forms creation in the English language can be regarded as an extensive dynamic process closely connected with the society need for optimization in terms of information transfer. Functional and semantic properties of abbreviations though discussed in a number of scientific disquisitions have not so far received all the attention they deserve, so we were trying to make the attempt to describe and analyse the semantic and functional properties of abbreviations both at the levels of language system and actual speech reality.

The units in question being designed in accordance with the linguistic norm and regularities of language demonstrate the abilities to be constructed on the basis of certain traditional structural models that may comprise both letters and sometimes figures combined with letters, as well as syllables and initial parts of the words contracted, to present the meaning of the prototype structure in the compressive way. As has been mentioned above, the process of abbreviation is determined by the principle of linguistic economy manifestation. Thus, the polycode nature of some abbreviations serves to optimize the process of information transfer.

The next important issue that should be mentioned is that abbreviation is a kind of ongoing process that constantly takes place in the reality and can be characterized by certain phases and bursts under the influence of various circumstances of linguistic and extralinguistic nature. As David Crystal writes, "The fashionable use of abbreviation - a kind of society slang - comes and goes in waves, though it is never totally absent. In the present century, however, it has been eclipsed by the emergence of abbreviations in science, technology, and other special fields, such as cricket, baseball, drug trafficking, the armed forces and the media" (Crystal, 2003, p. 120).

Abbreviated forms functioning in language possess linguistic properties of words and in the course of time may acquire their own lexical phraseological and morphological syntactic peculiarities due to their semantic independence and manifest linguistic peculiarities different from those of the prototype. This mostly lies within the sphere of discourse where abbreviations abundantly used subject to various influences of linguistic and extralinguistic character.

From the cognitive point of view abbreviations in terms of their creating and functioning refer to propositions, which concern with the process of codification and preservation at the mental level. Otherwise stated, propositions may be regarded as the mental structural basis of the abbreviation process determined by the nature of its prototype reference to the onomasiological model chosen for the contracted form creation. As for the cognitive communicative approach to abbreviation, it should be mentioned that creating and decoding abbreviation forms various types and formats of knowledge are included into the processes of speech production and speech perception as well as understanding and interpretation. As has been clearly shown above, the process of understanding the meaning of a unit in question refers to the background knowledge issue, that is knowledge shared by the representatives of a certain linguistic cultural or professional community.

In some cases, abbreviation due to its formal characteristics may stand very close to symbol, which demonstrates close interaction of different semiotic systems within language functioning taking into consideration both content and expression planes. At the same time very much depends on the context of abbreviations functioning in the actual speech reality, especially when concerned with homonymic or homographic contracted forms. This area of the research comprises various types of context, including cognitive context parameters, that stand close to the background knowledge issue.

The discursive approach to abbreviation analysis makes it possible to study new aspects of creation and functioning of abbreviations from the point of view of their realization in different varieties of English discourse. 
As has been shown above, both linguistic and extralinguistic factors should be taken into account, as well as situations, which stand apart from abbreviation employment for some extralinguistic reasons.

The analysis of abbreviation process within the political, business and public relations areas referring to the respective discourse varieties has shown that in all the spheres mentioned certain types of abbreviations are used to transfer information in the most precise way. It should be mentioned within these lines that one may come across the same abbreviations used in different discursive varieties thus being the sign marker of interdiscursivity. It is also important to note the diversity and rapid entry of certain abbreviation forms and models into the language, often used in the types of discourse under analysis and acquired the character of stable language expressions. They do not cause problems in their decoding and are also characterized by automatism being used by the linguistic cultural community representatives, thus facilitating communication process. Otherwise stated, the integrated approach that includes a number of methods appropriate for abbreviated forms investigation seems to be the most appropriate.

\section{References}

Academic dictionaries and encyclopedias. (2019). Retrieved from https://enacademic.com/

Arutyunova, N. D. (1976). The sentence and its sense: logical and semantic issues. M.: Nauka.

Bates, E. (1979). Intentions, conventions, and symbols. In E. Bates, L. Benigni, I. Bretherton, L. Camaioni \& V. Volterra (Eds.), The emergence of symbols. Academic Press. Retrieved from https://books.google.ru/books?hl=ru\&lr=\&id=bD60BQAAQBAJ\&oi=fnd\&pg=PP1\&ots=NpZont7bqq\&sig $=0 \mathrm{vNEEpAgqUnGL} \_\mathrm{vXUyETZucRc \_ 4 \& redir}$ esc $=\mathrm{y} \# \mathrm{v}=$ onepage $\& \mathrm{q} \& \mathrm{f}=\mathrm{false}$

Courtine, J.-J. (1981). Analyse du discourse politique (pp. 5-128) Paris: Languages.

Couthard, M., \& Montgomery, M. (ed.) (2015). Studies in Discourse Analysis. Routledge.

Crowley E. T. (2001). Acronyms, Initialisms, and Abbreviations Dictionary: A Guide to Alphabetic Designations, Contractions, Acronyms, Initialisms, Abbreviations, and Similar Condensed Appellations. Retrieved from http://muse.jhu.edu/article/460376

Crystal, D. (2001). Language and the Internet. Cambridge University Press. https://doi.org/10.1017/CBO9781139164771

Crystal, D. (2003). The Cambridge Encyclopedia of the English Language. English-Russian Dictionary. Retrieved from http://translate.academic.ru/MLE/en/ru

González, F. R., \& Cannon, G. (1994, March). Remarks on the Origin and Evolution of Abbreviations and Acronyms. Published online. https://doi.org/10.1075/cilt.113.26rod

Heywood, A. (2011). Global Politics. Palgrave Macmillan.

Hunt, T., \& Grunig, J. (1994). Public Relations Techniques. Orlando, Florida: Harcourt Brace College Publishers.

Kerswill, P. (2017). Contact, the feature pool and the speech community: The emergence of Multicultural London English. Retrieved from http://www.biling.su.se/polopoly_fs/1.91795.1339483992!/Kerswill_110111.pdf

Kubrjakova, E. S. (1981). Types of lexical meaning. Moscow: Nauka.

Kubryakova, E. S. (1986). Nominative aspect of speech activity. M: Nauka

Management tutorial. Retrieved from https://www.tutorialspoint.com

Marketing Teacher. Retrieved from https://www.marketingteacher.com

Merriam Webster Dictionary. Retrieved from https://www.merriam-webster.com/dictionary/abbreviations\#note-1

Minyar-Beloroucheva, A. (2015). Concept in statics and dynamics (in Russ.) South-Ural State University Bulletin, 12(1), 40-44.

Minyar-Beloroucheva, A., Sergienko, P., Vishnyakova, O., \& Vishnyakova, E. (2018). Modern technologies in teaching professionally oriented foreign language to the students of politics. In L. G. Chova, A. L. Martínez \& I. C. Torres (Eds.), ICERI 2018 Proceedings, 11th International Conference of Education, Research and Innovation (pp. 7967-7975), November 12th-14th, 2018, IATED Academy, Seville, Spain. https://doi.org/10.21125/iceri.2018.0043

Multicultural London English. Retrieved from http://en.wikipedia.org/wiki/Multicural_London_English 
Nilsen, D. L. F. (1981). Review of Acronyms, Initialisms, and Abbreviations Dictionary: A Guide to Alphabetic Designations, Contractions, Acronyms, Initialisms, Abbreviations, and Similar Condensed Appellations ed. by Ellen T. Crowley. Rocky Mountain Review of Language and Literature, 35(2), 157-159. https://doi.org/10.2307/1347807

Online Business Dictionary. Retrieved from http://www.businessdictionary.com

PR Dictionary. Retrieved from http://www.cipr.co.uk

Public Relations Defined: A modern Definition for the New Era of Public Relations. Retrieved from http://www.prdefinition.prsa.org

Public Relations Society of America (PRSA). Retrieved from https://www.prsa.org

Rosenberg, J. M. (1992). McGraw-Hill Dictionary of Business Acronyms, Initials, and Abbreviations. New York, USA: McGraw-Hill, Inc.

Sergienko, P. (2018). On the issue of PR terminology (a study of modern English) (in Russ.). Moscow State University Bulletin, 3, 58-65.

Third Door Media. (2018). Retrieved from https://thirddoormedia.com/news/

Use of Codes, Symbols, and Abbreviations. (2018). Added on 30 March 2018 in General News, Recent News. Retrieved from https://www.jointcommissioninternational.org/use-of-codes-symbols-and-abbreviations/

Van Dijk, T. A. (1997). Discourse as Structure and Process. L.: SAGE Publications Ltd.

Van Dijk, T. A. (2008). Discourse and Power. N.Y.: Palgrave Macmillan. https://doi.org/10.1007/978-1-137-07299-3

Van Dijk, T. A., \& Kintch, W. (1983). Strategies of Discourse Comprehension. N.Y., L.: Academic press.

Vishnyakova, O. (2018). Language as a tool of semantic interpretation (a study of modern English] (in Russ.). Moscow State University Bulletin, 1, 17-27.

Vishnyakova, O. D., Dobroradnykh, T. A., Aleksandrova, V. A., \& Klimanova, M. V. (2019). Knowledge and Linguistic Creativity Interaction in the Media Discourse. International Journal of English Linguistics, 9(2), 65-74. https://doi.org/10.5539/ijel.v9n2p65

What does MLE stand for? Retrieved from http://acronymsandslang.com/MLE-meaning.html

What does PR stand for? Retrieved from https://www.abbreviations.com/pr

\section{Copyrights}

Copyright for this article is retained by the author, with first publication rights granted to the journal.

This is an open-access article distributed under the terms and conditions of the Creative Commons Attribution license (http://creativecommons.org/licenses/by/4.0/). 